\title{
Impacts of AMSU-A, MHS and IASI data assimilation on temperature and humidity forecasts with GSI-WRF over the western United States
}

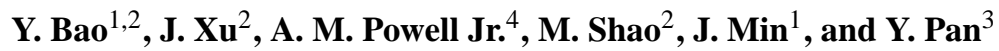 \\ ${ }^{1}$ Collaborative Innovation Center on Forecast and Evaluation of Meteorological Disasters, Key Laboratory for \\ Aerosol-Cloud-Precipitation of China Meteorological Administration, Nanjing University of Information \\ Science and Technology, Nanjing, China \\ ${ }^{2}$ Global Environment and Natural Resources Institute, College of Science, George Mason University, Fairfax, Virginia, USA \\ ${ }^{3}$ School of Atmospheric Science, Nanjing University, Nanjing, China \\ ${ }^{4}$ NOAA Center for Satellite Applications and Research (STAR), College Park, Maryland, USA
}

Correspondence to: J. Xu (jxu14@gmu.edu)

Received: 30 April 2015 - Published in Atmos. Meas. Tech. Discuss.: 25 June 2015

Revised: 7 September 2015 - Accepted: 2 October 2015 - Published: 14 October 2015

\begin{abstract}
Using NOAA's Gridpoint Statistical Interpolation (GSI) data assimilation system and NCAR's Advanced Research WRF (Weather Research and Forecasting) (ARWWRF) regional model, six experiments are designed by (1) a control experiment (CTRL) and five data assimilation (DA) experiments with different data sets, including (2) conventional data only (CON); (3) microwave data (AMSUA + MHS) only (MW); (4) infrared data (IASI) only (IR); (5) a combination of microwave and infrared data (MWIR); and (6) a combination of conventional, microwave and infrared observation data (ALL). One-month experiments in July 2012 and the impacts of the DA on temperature and moisture forecasts at the surface and four vertical layers over the western United States have been investigated. The four layers include lower troposphere (LT) from 800 to $1000 \mathrm{hPa}$, middle troposphere (MT) from 400 to $800 \mathrm{hPa}$, upper troposphere (UT) from 200 to $400 \mathrm{hPa}$, and lower stratosphere (LS) from 50 to $200 \mathrm{hPa}$. The results show that the regional GSI-WRF system is underestimating the observed temperature in the LT and overestimating in the UT and LS. The MW DA reduced the forecast bias from the MT to the LS within $30 \mathrm{~h}$ forecasts, and the CON DA kept a smaller forecast bias in the LT for 2-day forecasts. The largest root mean square error (RMSE) is observed in the LT and at the surface (SFC). Compared to the CTRL, the MW DA produced the most positive contribution in the UT and LS, and the CON DA mainly
\end{abstract}

improved the temperature forecasts at the SFC. However, the IR DA gave a negative contribution in the LT.

Most of the observed humidity in the different vertical layers is overestimated in the humidity forecasts except in the UT. The smallest bias in the humidity forecast occurred at the SFC and in the UT. The DA experiments apparently reduced the bias from the LT to UT, especially for the IR DA experiment, but the RMSEs are not reduced in the humidity forecasts. Compared to the CTRL, the IR DA experiment has a larger RMSE in the moisture forecast, although the smallest bias is found in the LT and MT.

\section{Introduction}

Instead of the random distribution and heterogeneous spatial density in the traditional conventional radiosondes, satellite observations provide a large amount of data covering worldwide areas in order to improve the initialization of the weather forecast models through a data assimilation system. Many studies have demonstrated that the assimilation of satellite data has significantly improved weather forecasts (Eyre, 1992; Andersson et al., 1991; Derber and Wu, 1998; Zhou et al., 2011), especially over some areas with sparse conventional observations (McNally et al., 2000; Zapotocny et al., 2008; Liu et al., 2012). For example, using the operational European Centre for Medium- 
Range Weather Forecasts (ECMWF) system, Andersson et al. (1991) pointed out that the forecast shows a negative impact of the satellite sounding data in the Northern Hemisphere, and a strong positive impact in the Southern Hemisphere. Based on the National Centers for Environmental Prediction (NCEP) Global Data Assimilation/Forecast System (GDAS/GFS), Zapotocny et al. (2008) found a positive forecast impact from both the conventional in situ and remotely sensed satellite data in both hemispheres. The positive forecast impacts from the conventional and satellite data are of similar magnitude in the Northern Hemisphere; however, the contribution to forecast quality from satellite data is considerably larger than the conventional data in the Southern Hemisphere. The importance of satellite data also generally increases at longer forecast times relative to conventional data. It is clear that satellite data assimilation plays an important role in the improvement of weather forecasts.

The Meteorological Operational satellite program (MetOp) launched its first polar-orbiting satellite (MetOp-A) on 19 October 2006. MetOp-A is in a sun-synchronous orbit, carrying a payload of 10 scientific instruments, including the Advanced Microwave Sounding Unit-A (AMSU-A), Microwave Humidity Sounder (MHS) and the new-generation Infrared Atmospheric Sounding Interferometer (IASI) to make atmospheric soundings at various altitudes. IASI (Clerbaux, et al., 2009) measures the radiance emitted from the Earth in 8461 channels covering the spectral interval $645-2760 \mathrm{~cm}^{-1}$ at a resolution of $0.5 \mathrm{~cm}^{-1}$ (apodized) and with a spatial sampling of $18 \mathrm{~km}$ at nadir. Limited spectral data are currently being transmitted, stored and assimilated. Rabier et al. (2002) compared a number of techniques for channel selection from high-spectral-resolution infrared sounders and concluded that the channel-selection method of Rodgers $(1996,2000)$ is the optimal one. Collard (2007) applied his method to select a subset of 300 channels for data assimilation, so that the total loss of information for a typical numerical weather prediction (NWP) state vector consisting of one or more of temperature and/or humidity is minimized.

This study focuses on assessing the effects of hyperspectral infrared and microwave radiance data assimilation on the weather forecasts, especially on the different performance of vertical structures, based on AMSU-A, MHS and IASI radiance data. The model, data and methodology are presented in Sects. 2 and 3, respectively. Section 4 describes the results of experiments. The results are summarized and discussed in Sect. 5.

\section{Model}

\subsection{The GSI system for ARW-WRF regional model}

The assimilation system used here is the Gridpoint Statistical Interpolation (GSI) analysis system, which was developed by United States National Centers for Environmental Pre- diction (NCEP). The current GSI regional analysis system accepts NCEP's Nonhydrostatic Mesoscale Model (NMM) WRF and NCAR's Advanced Research WRF (Weather Research and Forecasting) (ARW-WRF) regional model mass core (Liu and Weng, 2006a; Xu and Powell, 2012; Wan and $\mathrm{Xu}, 2011)$. The interfaces are specialized separately for the WRF NMM core and the WRF ARW core. The analysis system produces an analysis through the minimization of an objective function given by

$J=\frac{1}{2}\left(x-x^{b}\right)^{T} B^{-1}\left(x-x^{b}\right)+\frac{1}{2}\left(H(x)-y^{\mathrm{o}}\right)^{T} R^{-1}\left(H(x)-y^{\mathrm{o}}\right)$,

where $x$ is the analysis state; $B$ is the background error covariance matrix; $x^{b}$ is the first guess that comes from GFS $6 \mathrm{~h}$ forecast field in this study; $H$ is the transformation operator from the analysis variable to the form of the observations; and $y^{\circ}$ is the observation, such as AMSU-A, MHS, IASI, etc.

The minimization algorithm with two outer iterations proposed in John Deber's report (Deber, 2012) has been verified and used in NOAA operational forecasts. Therefore, the minimization algorithm is used to account for weak nonlinearities in the cost function. In the first external iteration the first guess is a $6 \mathrm{~h}$ forecast, while in the second one it is the solution from the previous outer iteration. In the cost function $B$ has been estimated from scaled differences between 24 and $48 \mathrm{~h}$ forecasts valid at the same time (Parrish and Derber, 1992). The observation error covariance matrix $(R)$ contains information on the observational error and errors in representativeness, which were calculated before running the GSI.

\subsection{Radiative transfer model}

The radiative transfer model incorporated into the GSI data assimilation system at the NCEP is the Community Radiative Transfer Model (CRTM). The CRTM was developed by the United States Joint Center for Satellite Data Assimilation (JCSDA) for rapid calculations of satellite radiances based on radiative transfer (RT) theory (Han et al., 2006). The forward model, tangent-linear, adjoint and K-matrix models were also developed for the data assimilation of satellite data: CRTM is always updated for new satellite data. It supports a large number of sensors onboard geostationary and polarorbiting satellites, covering the microwave, infrared and visible frequency regions.

The CRTM comprises four major modules: (1) RT solution module, (2) atmospheric transmittance module, (3) surface emissivity/reflectivity module, and (4) particle-scattering module. Six RT solution schemes were tested in the CRTM (Weng et al., 2007). According to several performance factors, the advance doubling and adding scheme (ADA; Liu and Weng, 2006a) was selected for the CRTM implementation. In CRTM, a fast and optimal spectral sampling (OSS) absorption model (Moncet et al., 2004) is used to calculate atmospheric transmittance. 
Table 1. The experiment design includes six simulations (EXP1-EXP6). All experiments are made from 30 June to 31 July 2012 and make a $72 \mathrm{~h}$ forecast for each day.

\begin{tabular}{llll}
\hline & Experiment & Description & Initial time \\
\hline EXP1 & CTRL & Control experiment without data assimilation & 18:00 UTC from 30 June to 31 July \\
EXP2 & CON & Conventional data assimilation & 00:00 UTC from 1 to 31 July \\
EXP3 & MW & AMSU-A + MHS data assimilation & 00:00 UTC from 1 to 31 July \\
EXP4 & IR & IASI data assimilation & $00: 00$ UTC from 1 to 31 July \\
EXP5 & MWIR (MW + IR) & AMSU-A + MHS + IASI data assimilation & 00:00 UTC from 1 to 31 July \\
EXP6 & ALL (CON+MW + IR) & Conventional + AMSU-A + MHS + IASI data assimilation & 00:00 UTC from 1 to 31 July \\
\hline
\end{tabular}
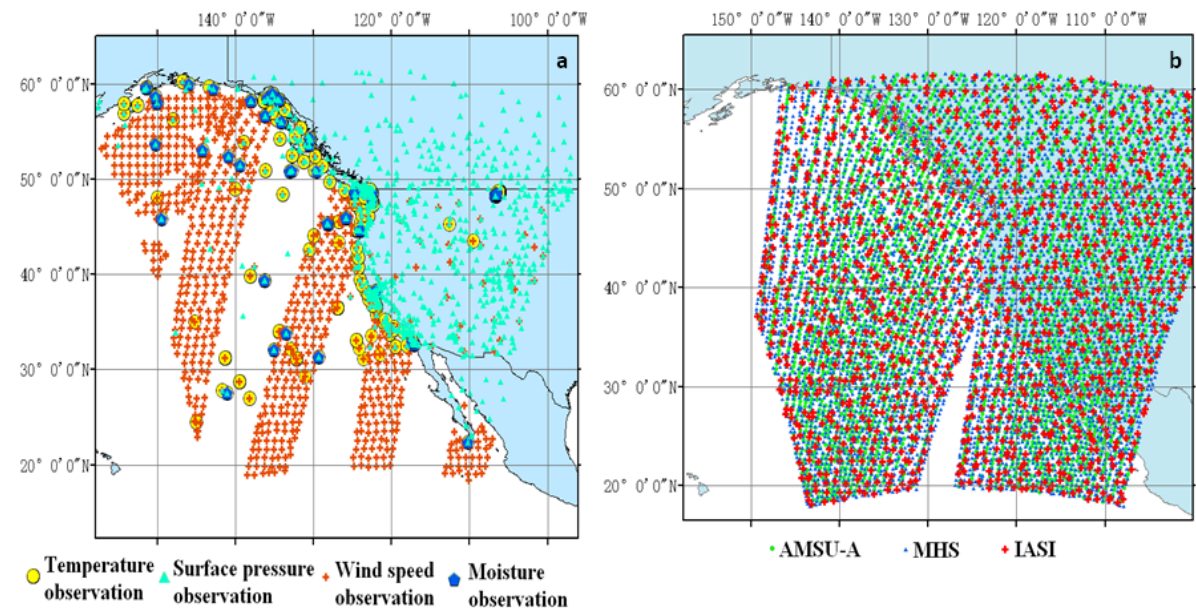

Figure 1. Distribution of observations. (a) Conventional data on 1 July 2012 with the atmospheric temperature (yellow), moisture (dark blue), surface pressure (light blue), and wind speed (orange). (b) Scan coverage of AMSU-A (light blue), MHS (dark blue) and IASI (red) radiance at 18:00 UTC on 1 July 2012

\subsection{Experiment design}

The objective of this study is to explore the effect of satellite data assimilation on the main atmospheric state forecast by comparing the results from microwave (AMSU-A and MHS), hyperspectral infrared radiance (IASI) and conventional data assimilation. Over the contiguous United States of America (USA), there are many conventional observation stations, which can be used to validate the forecast results. Therefore, the west coast region of the USA is selected as the experimental region. There was more satellite data coverage of the experimental region around 18:00 UTC than at other times, such as 00:00, 06:00 and 12:00 UTC. The covered region at $18: 00 \mathrm{UTC}$ is $20-55^{\circ} \mathrm{N}$ and $85-155^{\circ} \mathrm{W}$, which includes the western USA and sea area near the west coast (Fig. 1).

The experiment design includes six simulations (Table 1). The control (CTRL) experiment is first made with an initial time at 18:00 UTC from 30 June to 30 July and makes $6 \mathrm{~h}$ forecasts. The five data assimilation (DA) experiments and the continued control experiment are made with initial time at 00:00 UTC from 1 to 31 July 2012 and make a $72 \mathrm{~h}$ forecast for each day. The initial condition in all six exper- iments is obtained from the $6 \mathrm{~h}$ forecasts of the first control experiment. The five DA experiments are made with different data sets, including conventional data $(\mathrm{CON})$; microwave data (AMSU-A + MHS) (MW); infrared data (IASI) (IR); a combination of microwave and infrared data (MWIR); and a combination of conventional, microwave and infrared observation data (ALL). The initial condition and lateral boundary conditions came from the operational GFS forecast at $6 \mathrm{~h}$ intervals and $0.5^{\circ} \times 0.5^{\circ}$ resolution, which were downloaded from the NCEP data inventory (ftp://ftp.ncep.noaa.gov/pub/ data/nccf/com/gfs/prod/).

In the ARW model, the physics of the model includes the Goddard Cumulus Ensemble (GCE) microphysics scheme, Yonsei University planetary boundary layer (PBL) scheme, Noah land surface model, Rapid Radiative Transfer Model (RRTM) longwave radiation, and the Goddard shortwave radiation scheme (Xu et al., 2009). The $15 \mathrm{~km}$ WRF model forecast with a mesh size domain of $718 \times 373$ (Fig. 1) was used. Forty-three (43) vertical layers were selected for use with a model top of $10 \mathrm{hPa}$. 

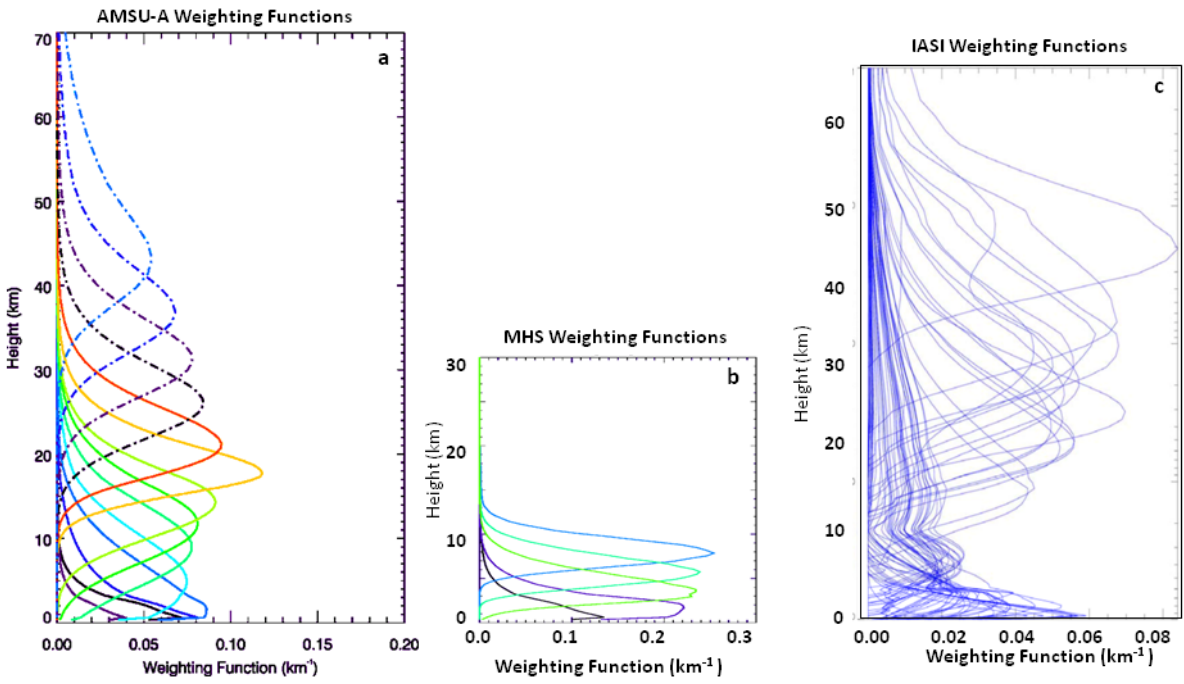

Figure 2. Vertical weighting functions for satellite observations as a function of height. (a) AMSUA, (b) MHS , (c) IASI.

Table 2. Listed below are the 279 channels in IASI corresponding to atmospheric temperature and humidity. The numbers indicate the order in which the channels were chosen in current data assimilation.

\begin{tabular}{llllllllll}
\hline 16 & 135 & 226 & 356 & 566 & 1658 & 2993 & 3248 & 3509 & 5502 \\
38 & 138 & 230 & 360 & 571 & 1671 & 3002 & 3252 & 3518 & 5507 \\
49 & 141 & 232 & 366 & 573 & 1786 & 3008 & 3256 & 3527 & 5509 \\
51 & 144 & 236 & 371 & 646 & 1805 & 3014 & 3263 & 3555 & 5517 \\
55 & 146 & 239 & 373 & 662 & 1884 & 3027 & 3281 & 3575 & 5558 \\
57 & 148 & 243 & 375 & 668 & 1991 & 3029 & 3303 & 3577 & 5988 \\
59 & 151 & 246 & 377 & 756 & 2019 & 3036 & 3309 & 3580 & 5992 \\
61 & 154 & 249 & 379 & 867 & 2094 & 3047 & 3312 & 3582 & 5994 \\
63 & 157 & 252 & 381 & 906 & 2119 & 3049 & 3322 & 3586 & 6003 \\
66 & 159 & 254 & 383 & 921 & 2213 & 3053 & 3375 & 3589 & \\
70 & 161 & 260 & 386 & 1027 & 2239 & 3058 & 3378 & 3599 & \\
72 & 163 & 262 & 389 & 1046 & 2271 & 3064 & 3411 & 3653 & \\
74 & 167 & 265 & 398 & 1121 & 2321 & 3069 & 3438 & 3658 & \\
79 & 170 & 267 & 401 & 1133 & 2398 & 3087 & 3440 & 3661 & \\
81 & 173 & 269 & 404 & 1191 & 2701 & 3093 & 3442 & 4032 & \\
83 & 176 & 275 & 407 & 1194 & 2741 & 3098 & 3444 & 5368 & \\
85 & 180 & 282 & 410 & 1271 & 2819 & 3105 & 3446 & 5371 & \\
87 & 185 & 294 & 414 & 1479 & 2889 & 3107 & 3448 & 5379 & \\
104 & 187 & 296 & 416 & 1509 & 2907 & 3110 & 3450 & 5381 & \\
106 & 193 & 299 & 426 & 1513 & 2910 & 3127 & 3452 & 5383 & \\
109 & 199 & 303 & 428 & 1521 & 2919 & 3136 & 3454 & 5397 & \\
111 & 205 & 306 & 432 & 1536 & 2939 & 3151 & 3458 & 5399 & \\
113 & 207 & 323 & 434 & 1574 & 2944 & 3160 & 3467 & 5401 & \\
116 & 210 & 327 & 439 & 1579 & 2948 & 3165 & 3476 & 5403 & \\
119 & 212 & 329 & 445 & 1585 & 2951 & 3168 & 3484 & 5405 & \\
122 & 214 & 335 & 457 & 1587 & 2958 & 3175 & 3491 & 5455 & \\
125 & 217 & 345 & 515 & 1626 & 2977 & 3178 & 3497 & 5480 & \\
128 & 219 & 347 & 546 & 1639 & 2985 & 3207 & 3499 & 5483 & \\
131 & 222 & 350 & 552 & 1643 & 2988 & 3228 & 3504 & 5485 & \\
133 & 224 & 354 & 559 & 1652 & 2991 & 3244 & 3506 & 5492 & \\
\hline & & & & & & & & &
\end{tabular}

\section{Data and methodology}

\subsection{Conventional and satellite data}

In this study the conventional observation data include atmospheric temperature $(T)$, moisture $(Q)$ and wind speed
(WSP) at various pressure levels and pressure data at the surface that were downloaded from NCEP data inventory (ftp: //ftp.ncep.noaa.gov/pub/data/nccf/com/gfs/prod/). Figure 1a shows the distribution of the conventional data on 1 July 2012 where the atmospheric temperature, moisture and surface pressure observations are rare. Most of atmospheric temperature and moisture observations are conducted at the surface level in the pressure range of 1000-1200 hPa. Most of the WSP data are found over the sea close to the west coast of the United States.

The satellite data include the AMSU-A, MHS and the new-generation IASI. Figure $1 \mathrm{~b}$ shows the distribution of the AMSU-A, MHS and IASI data sets acquired at about 18:00 UTC on 1 July 2012. AMSU-A is a 15-channel crosstrack, stepped-line scanning, total power microwave radiometer. In this study the channels from 4 to 14 are assimilated, which were designed to detect atmospheric temperature at 11 layers from the surface to around $45 \mathrm{~km}$. Their weighting function is illustrated in Fig. 2a. MHS on the other hand probes at millimetric frequencies between 89 and $183 \mathrm{GHz}$; channels 2 to 5 are assimilated, which were designed to detect atmospheric moisture at two layers from surface to around $400 \mathrm{hPa}$. Their weighting function is illustrated in Fig. 2b. Channel 4 of AMSU-A and channel 2 of MHS can detect the atmospheric temperature and humidity at the lowest layer of the troposphere. Channels 5 and 6 of AMSU-A and channels 3, 4 and 5 of MHS can represent the atmospheric temperature and humidity in the middle atmospheric layer of the troposphere. Channel 7 of AMSU-A can indicate the atmospheric temperature in the highest layer of troposphere. Channels 9 and 10 of AMSU-A can detect the atmospheric temperature in the lower layer of the stratosphere. 

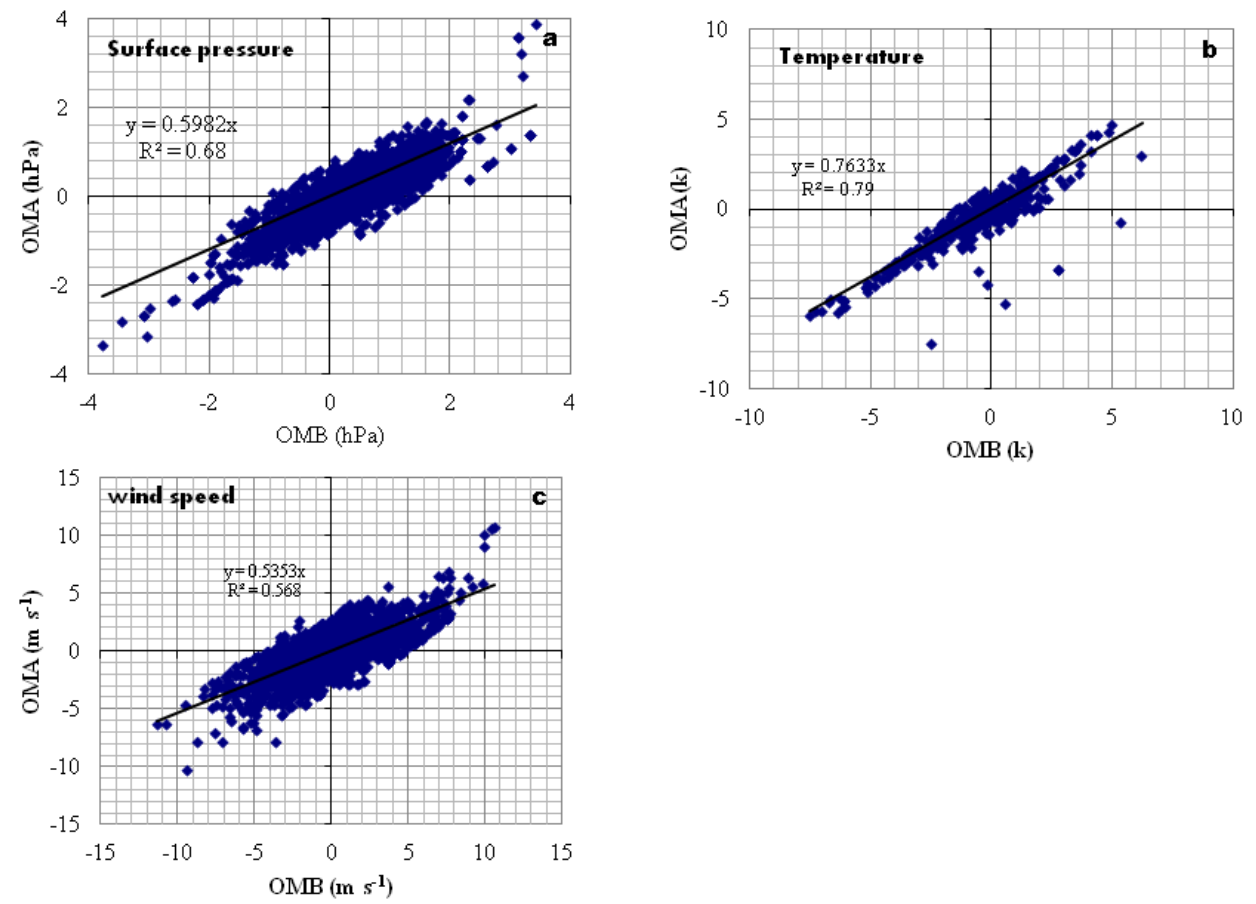

Figure 3. The scattering plot between observation minus background (OMB) and observation minus analysis (OMA) in the all-data $(\mathrm{CON}+\mathrm{AMSU}-\mathrm{A}+\mathrm{MHS}+\mathrm{IASI})$ experiment (a: surface pressure; $\mathbf{b}$ : atmospheric temperature at the height of $2 \mathrm{~m}$; $\mathbf{c}$ : wind speed at the height of $10 \mathrm{~m}$ ) for 1 July 2012.

The IASI instrument covers the spectral range from the thermal infrared at $3.62 \mu \mathrm{m}\left(2760 \mathrm{~cm}^{-1}\right)$ to $15.5 \mu \mathrm{m}$ $\left(645 \mathrm{~cm}^{-1}\right)$, covering the peak of the thermal infrared and particularly the $\mathrm{CO}_{2}$ band with the humidity $(Q)$ branch around $666 \mathrm{~cm}^{-1}$. Within these bands, the selected 279 bands (Table 2) correspond to atmospheric temperature and humidity. A band number smaller than 515 represents atmospheric temperature, and a band number larger than 2701 represents atmospheric humidity. Their weighting function is illustrated in Fig. 2c.

\subsection{Radiance data quality control and bias correction}

The radiance data have been preprocessed by NOAA's Satellite and Information Service (NESDIS) before becoming available for usage. The data have been statistically limb-corrected (adjusted to nadir) and surface-emissivitycorrected in the microwave channels and cloud-cleared in the tropospheric channels. Although the satellite data have undergone preprocessing, they need further bias correction before being ingested into the data assimilation system. The source of the biases can be related to instrument calibration problems, and predictor and zenith angle bias. It has been demonstrated that a successful bias correction scheme must take into account the spatially varying and air-massdependent nature of radiance biases (Kelly and Flobert, 1988; McMillin et al., 1989; Uddstrom, 1991). Eyre (1992) and Harris and Kelly (2001) categorized the bias into two types: scan bias and air-mass bias, and they presented a bias correction scheme. GSI uses this bias correction scheme to correct radiance bias. The radiance bias correction coefficients may be downloaded from the GDAS data directory (ftp://ftp.ncep.noaa.gov/pub/data/nccf/com/gfs/prod/), and it can be used to correct the radiance bias in GSI. For that purpose in this study monthly regional mean innovations, e.g., observation minus background (OMB) and observation minus analysis (OMA), are calculated with or without bias corrections. For example, Fig. 3 shows the scattering plots of surface pressure (Fig. 3a), atmospheric temperature at the height of $2 \mathrm{~m}$ (Fig. 3b) and wind speed at the height of $10 \mathrm{~m}$ (Fig. 3c) between OMB and OMA in the ALL experiment. The result shows that the slope of the simulated line is less than 1 , which indicates the analysis fields are closer to observation than background fields.

\subsection{Methodology}

In order to evaluate the effects of radiance data assimilation on temperature and moisture at the different vertical layers, the surface (SFC) and four atmospheric layers are examined. The four layers include lower troposphere (LT) from 800 to $1000 \mathrm{hPa}$, middle troposphere (MT) from 400 to $800 \mathrm{hPa}$, upper troposphere (UT) from 200 to $400 \mathrm{hPa}$ and lower stratosphere (LS) from 50 to $200 \mathrm{hPa}$. Similar to a previous study (Xu, et al., 2009), two statistical variables - bias and root mean square errors (RMSEs) - are investigated. 

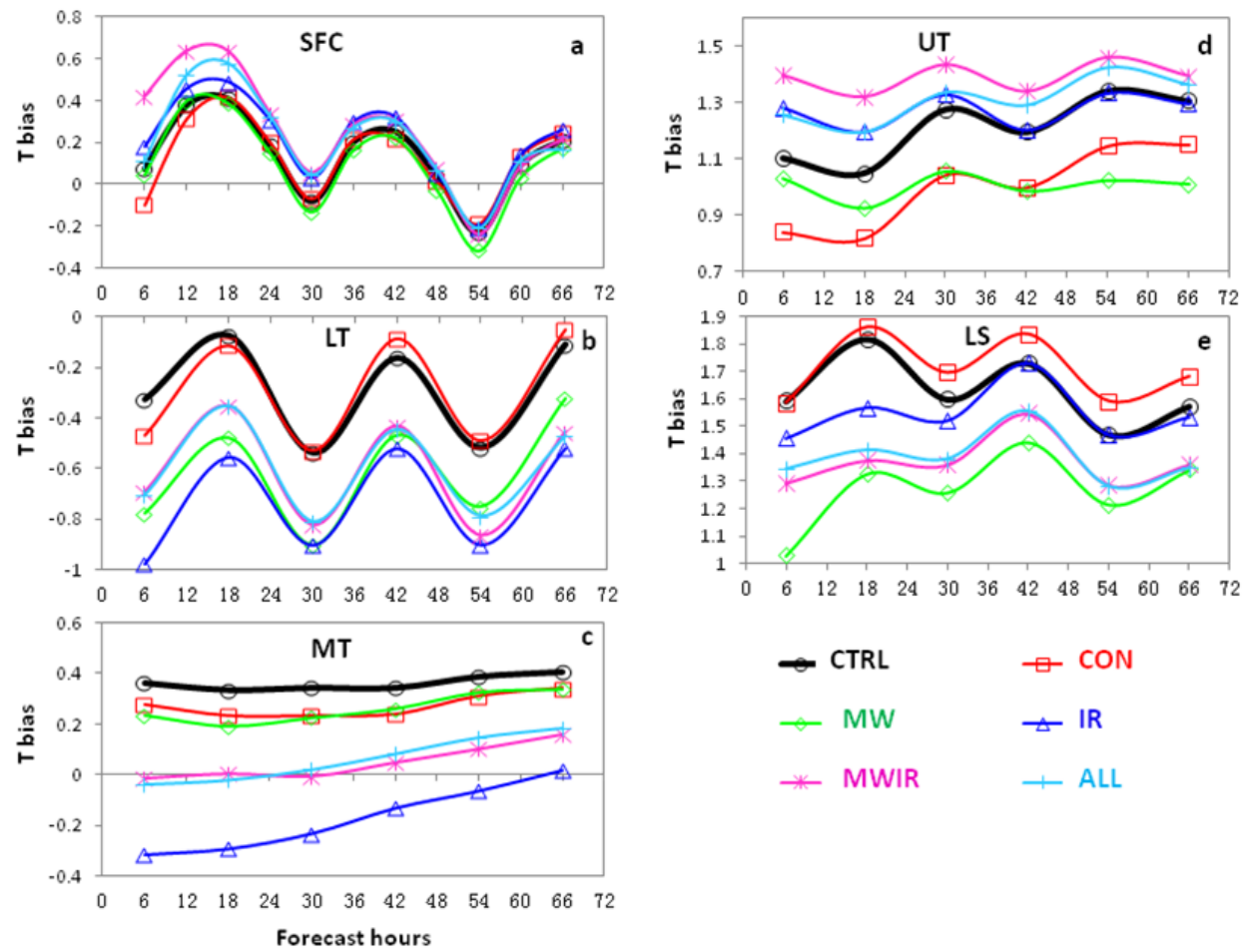

Figure 4. Bias of the temperature $(T)$ forecasts at (a) surface (SFC), (b) lower troposphere (LT), (c) middle troposphere (MT), (d) upper troposphere (UT), (e) lower stratosphere (LS). Unit: ${ }^{\circ} \mathrm{C} . \mathrm{CTRL}, \mathrm{CON}, \mathrm{MW}, \mathrm{IR}, \mathrm{MWIR}$ and ALL are defined in Table 1.

If $X$ represents any of the parameters under consideration for a given time and vertical level, then the forecast error is defined as $X^{\prime}=X_{\mathrm{f}}-X_{\mathrm{o}}$, where the subscripts $f$ and $o$ denote forecast and observed quantities, respectively. Given $N$ valid pairs of forecasts and observations, the bias is computed as

bias $=\overline{X^{\prime}}=\frac{1}{N} \sum_{i=1}^{N} X_{i}^{\prime}$

the RMSE is computed as

RMSE $=\sqrt{\frac{1}{N} \sum_{i=1}^{N}\left(X_{i}^{\prime}\right)^{2} .}$

The bias and RMSE at 00:00 and 12:00 UTC are calculated because more than enough observational data and approximately 3000 sounding stations can be used at the two times.

\section{Results}

\subsection{Impact of DA on temperature}

At the SFC, the CON DA experiment shows (Fig. 4a) the smallest bias value in all six experiments. The three involved infrared satellite DA experiments (IR, IR $+\mathrm{MW}$, $\mathrm{IR}+\mathrm{MW}+\mathrm{CON}$ ) show a larger bias than the CTRL experiment. For the first $24 \mathrm{~h}$, it seems that satellite radiance DA, especially for the infrared IASI data, gives a negative contribution to the temperature forecasts. In additon, the bias characterized a diurnal cycle feature for the $72 \mathrm{~h}$ forecasts, with the smaller bias appearing at $6,30,54$ and $72 \mathrm{~h}$, corresponding to 16:00 LT, while the higher bias appeared at 18, 42 and $66 \mathrm{~h}$, corresponding to 04:00 local time.

Compared to the SFC, the LT shows a more clear diurnal variation (Fig. 4b), and all model forecasts underestimated the observed temperature. The CTRL and CON experiments obtained the smallest forecast bias.

Different from the SFC and LT, the diurnal variation of bias disappeared in the MT (Fig. 4c). Compared to the CTRL experiment, the bias is significantly reduced in all DA experiments, especially for the two combination experiment (MWRI and ALL); the bias is almost zero within the $30 \mathrm{~h}$ forecast. It implies that both MW (AMUS-A and MHS) and IR (IASI) DA experiments give a positive contribution to the accuracy of temperature forecasts in the MT.

In the UT, the smaller bias appeared in the CON and MW DA experiments (Fig. 4d), and the combination DA experiments (MWIR and ALL) show a larger bias than the CTRL experiment. The results indicate that the IR DA gave a negative contribution to the temperature forecasts and that the MW experiment improved the forecast accuracy in the UT.

In contrast, the bias in the LS indicates an opposite pattern to the SFC and LT, where all satellite DA experiments reduced the forecast bias (Fig. 4e). The result demonstrated 

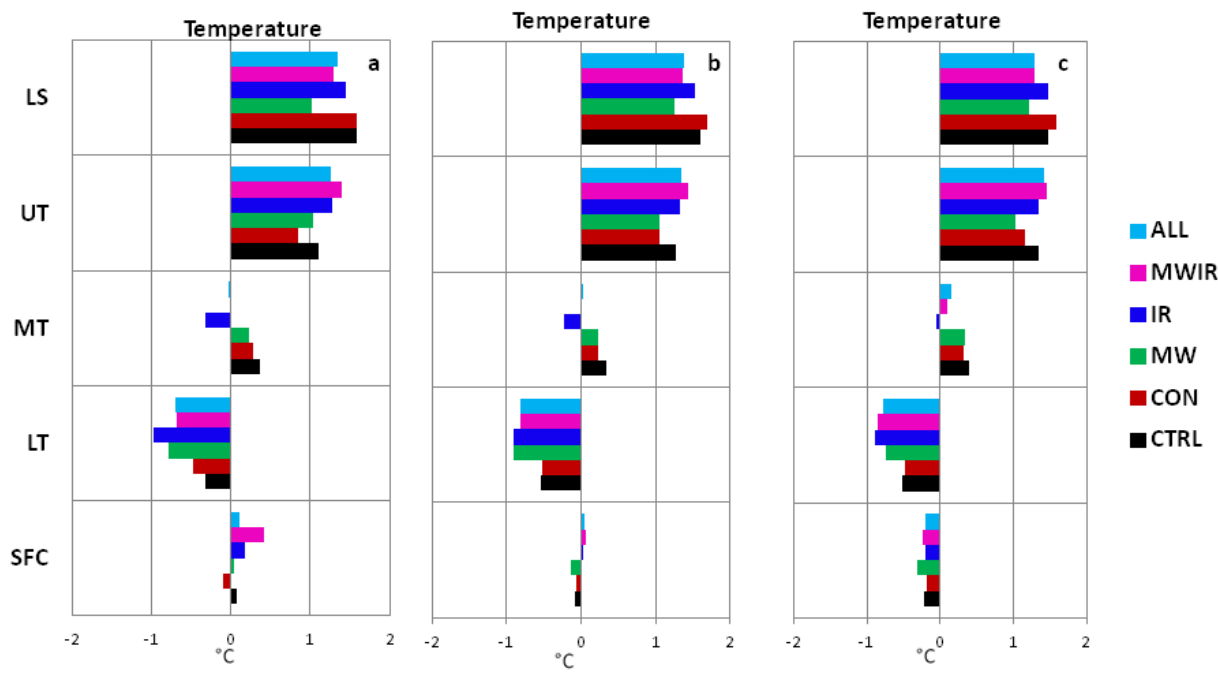

Figure 5. Bias profile of the temperature (T) forecasts at (a) $6 \mathrm{~h},(\mathbf{b}) 30 \mathrm{~h}$, (c) $54 \mathrm{~h}$ forecasts. Unit: ${ }^{\circ} \mathrm{C}$. Other definitions are the same as in Fig. 4.

that the conventional DA did not improve the forecasts because of the sparse observational data used in this layer. The MW DA obtained the smallest bias in the LS.

In order to clearly understand the different performance in the six experiments, the temperature forecast bias profile at 6,30 and $54 \mathrm{~h}$ has been examined. Figure 5 indicates a similar pattern at the three forecast times, where the lower bias can be found at the SFC and in the MT while the larger bias appeared in the UT and LS. Generally, the model forecasts overestimated the observed temperature except in the LT. Compared to the CTRL experiment, the four satellite DA experiments (MW, IR, MWIR and ALL) show a smaller bias from the MT through LS, but the forecasts did not improve in the LT below $800 \mathrm{hPa}$. In contrast, the CON experiment has better performance in the LT, especially at the SFC.

It is obvious that the larger bias in temperature forecast appeared in the LT, UT and LS, but the model is underestimating the observed temperature in the LT and overestimating in the UT and LS (Fig. 5). The satellite DA, especially for the MW DA experiment using AMSU-A, reduced the forecast bias at the levels from the MT to LS. Meanwhile, the CON DA has a smaller forecast bias in the LT, especially at the SFC. Note the IR experiment using the IASI data produced a worse result in the LT.

The forecast RMSE demonstrated some different features (Fig. 6). First, the RMSE reduced the diurnal variation and significantly increased with the extended length of forecast time at the SFC. The RMSE in the CON and MW experiments is slightly less than that in the CTRL experiment and the other three satellite DA experiments within $24 \mathrm{~h}$ forecasts (Fig. 6a). Second, consistent with the larger negative bias in all the satellite DA experiments (Fig. 4b) in the LT, larger RMSEs are observed in these DA experiments (Fig. 6b) compared to the CRTL. Third, different from the smaller bias in the DA experiments, the larger RMSEs are maintained in the DA experiments in the MT (Fig. 6c). Fourth, the CON and MW experiments improved the temperature forecasts in the UT (Fig. 6d). But in the LS, the microwave DA experiments - including MW, MWIR and ALL - indicate smaller RMSEs than the CTRL experiment (Fig. 6e). It is apparent that the CON DA gave a negative contribution to the temperature forecast in the LS.

Corresponding to the bias profile (Fig. 5), the forecast RMSE profile at 6, 30 and $54 \mathrm{~h}$ indicates (Fig. 7) that the smallest RMSE is observed at the MT and the largest RMSE appeared in the LT and SFC. Compared to the CTRL experiment, the smaller RMSEs are only found in the MW experiment in the UT and LS, and the CON DA gave a positive contribution at the SFC and in the UT.

The results clearly show that the IR DA experiment gives a negative contribution to the temperature forecast in the regional system. But the MW DA experiment shows a positive impact at the LS, and the CON experiment displays better performance at the SFC and in the UT. It is worth noticing that the RMSE is not always consistent with the bias in the temperature forecasts; for example, the smaller bias appeared at the SFC, while a larger RMSE is observed there.

\subsection{Impact of DA on humidity}

Similar to the temperature forecasts at the SFC, the diurnal variation of the moisture bias is observed and the smallest bias appeared in the CON and CTRL experiments within the $42 \mathrm{~h}$ forecast (Fig. 8a), with largest bias occurring in the MWIR experiment at $18 \mathrm{~h}$. It is clear that all four satellite DA experiments do not improve the moisture forecast compared to the CTRL experiment. In contrast, the IR DA produced a larger bias significantly different from the other ex- 

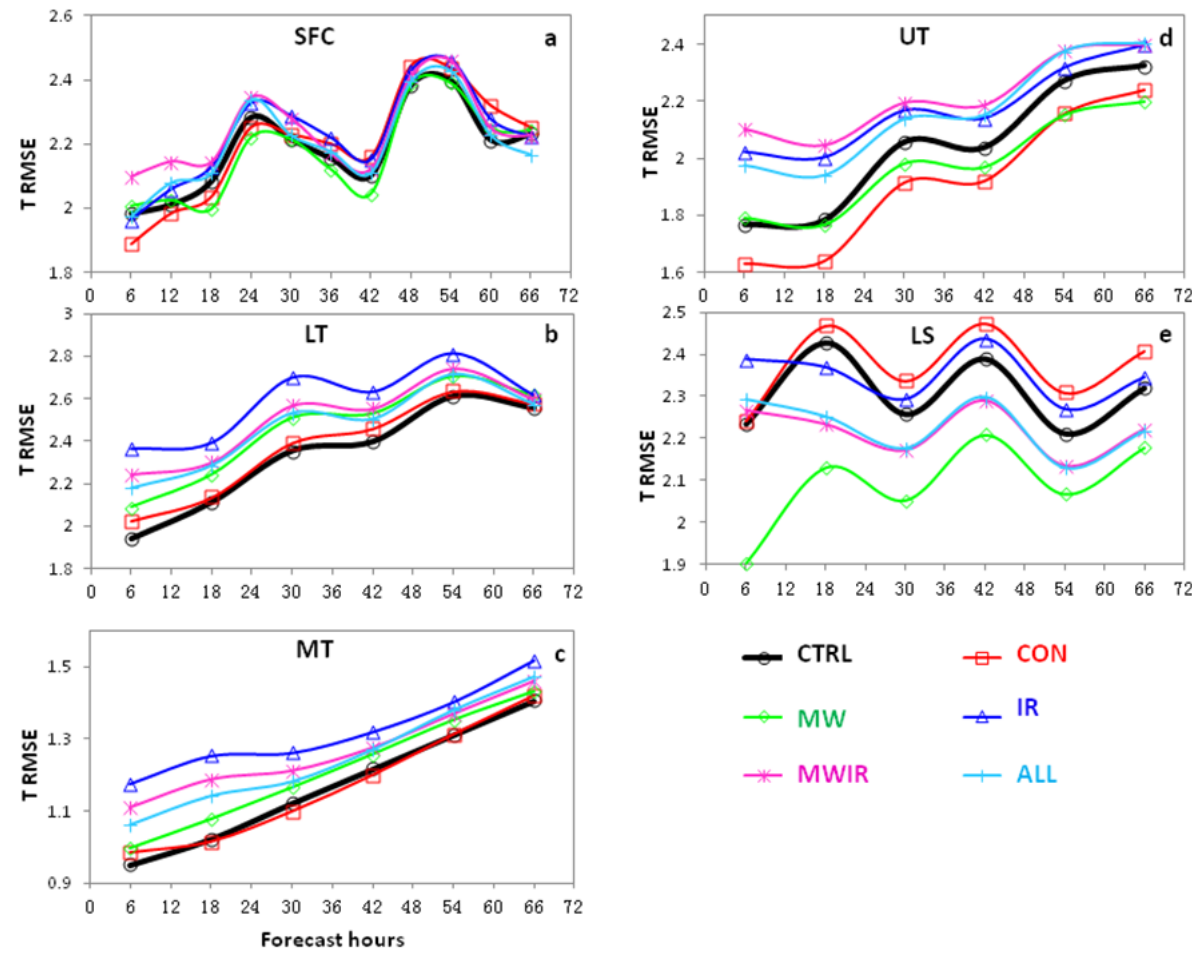

Figure 6. RMSE of the temperature ( $T$ ) forecasts at (a) surface (SFC), (b) lower troposphere (LT), (c) middle troposphere (MT), (d) upper troposphere, (e) lower stratosphere. Unit: ${ }^{\circ} \mathrm{C}$. Other definitions can be found in Table 1.
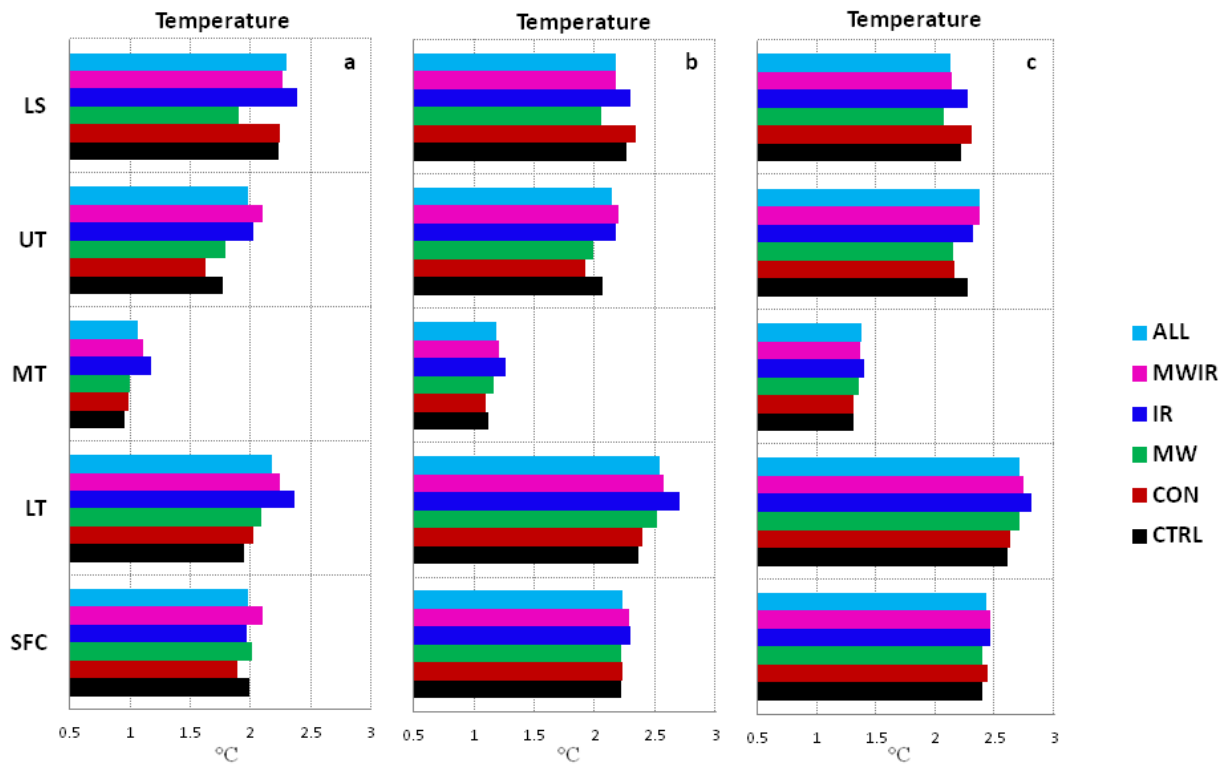

Figure 7. The RMSE profile of the temperature forecasts at (a) $6 \mathrm{~h}$, (b) $30 \mathrm{~h}$, (c) $54 \mathrm{~h}$ forecasts. Unit: ${ }^{\circ} \mathrm{C}$. Other definitions are the same as in Fig. 4.

periments in the entire troposphere (Fig. 8b-d). It seems to tell us that the IR DA significantly impacts the humidity forecasts in the troposphere. However, the impact disappeared in the LS (Fig. 8e).
Compared to the bias profile of the temperature forecast (Fig 4), all model runs overestimated the observed humidity except for the UT. The smallest bias in the humidity forecast occurred at the SFC and in the UT (Fig. 9). Most of the DA experiments apparently reduced the bias from LT to UT, es- 

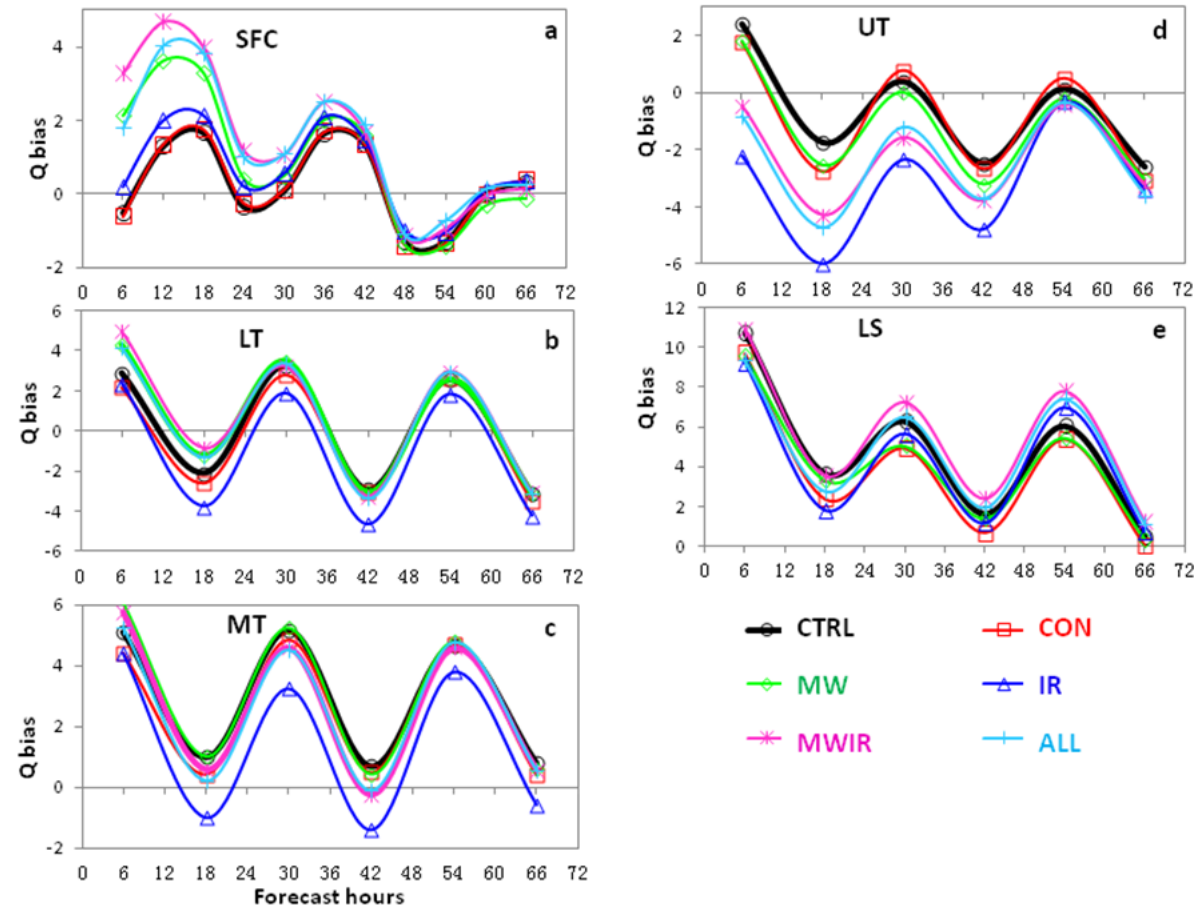

Figure 8. The bias of the specific humidity $(Q)$ forecasts at (a) surface (SFC), (b) lower troposphere (LT), (c) middle troposphere (MT), (d) upper troposphere, (e) lower stratosphere. Unit: $\mathrm{g} \mathrm{kg}^{-1}$. Other definitions can be found in Table 1.
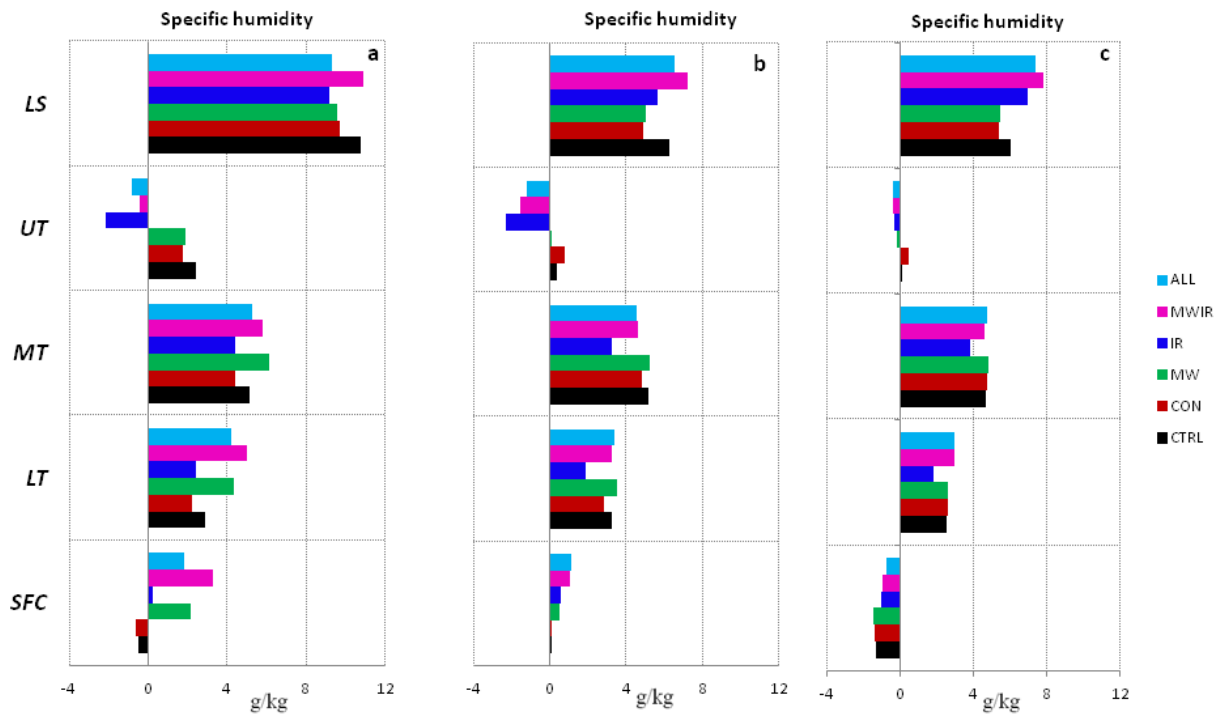

Figure 9. Bias profile of the specific humidity forecasts at (a) $6 \mathrm{~h}$, (b) $30 \mathrm{~h}$, (c) $54 \mathrm{~h}$ forecasts. Unit: $\mathrm{g} \mathrm{kg}^{-1}$. Other definitions are the same as in Fig. 4.

pecially for the IR experiment. But it is worth noting that the MW DA has a larger bias than the CTRL experiment in the whole troposphere.

However, the RMSE in the humidity forecasts (Fig. 10) increases from the SFC to LS. The largest error in the UT and LS is almost double the amount at the SFC. In addition, most of the DA experiments demonstrated a larger RMSE than that in the CTRL experiment. In other words, the DA experiments gave a negative contribution to the humidity forecasts. The IR DA experiment did not improve moisture forecast, although its bias is very small at the LT and MT. 

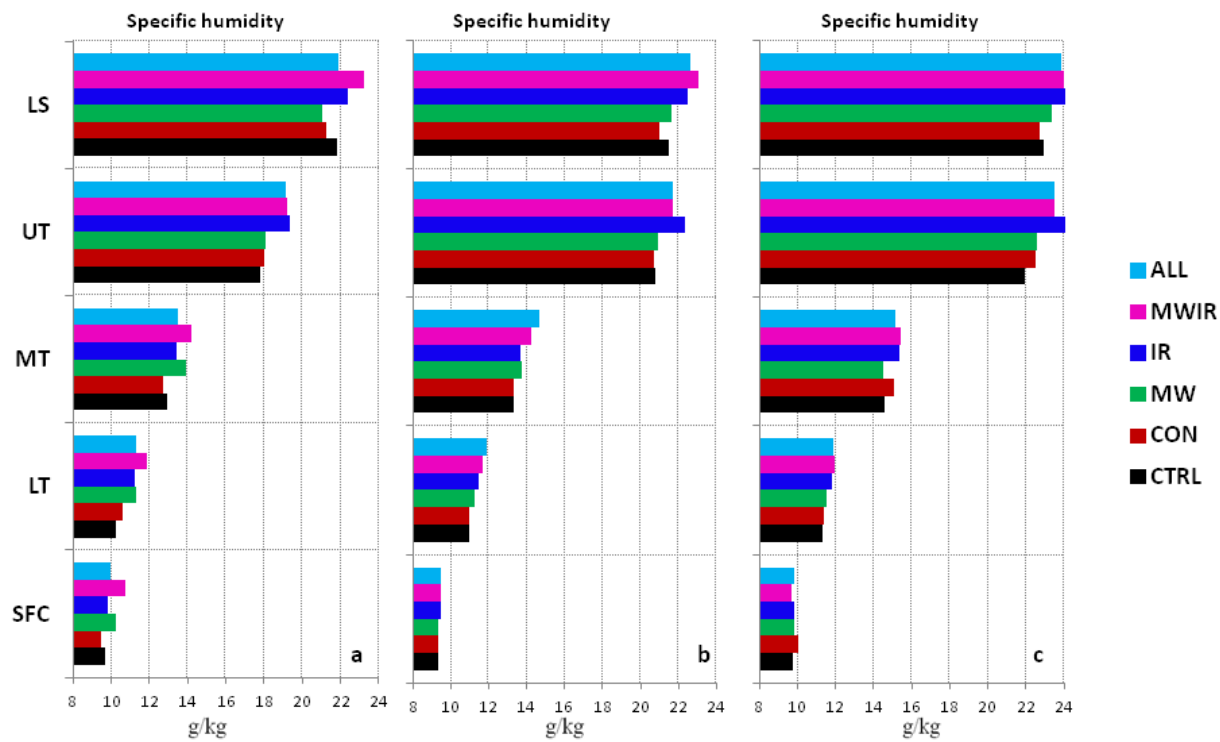

Figure 10. The RMSE profile of the specific humidity forecasts at (a) $6 \mathrm{~h}$, (b) $30 \mathrm{~h}$, (c) $54 \mathrm{~h}$ forecasts. Unit: $\mathrm{g} \mathrm{kg}^{-1}$. Other definitions are the same as in Fig. 4.

\section{Summary and discussion}

\subsection{Summary}

In this study six experiments were designed to assess the effects of data assimilation on atmospheric temperature and moisture forecasts over the western United States. The results are summarized as follows.

The regional model underestimates the observed temperature in the LT and overestimates it in the UT and LS. The MW experiment reduced the forecast bias from the MT to LS, and the CON DA obtained a smaller forecast bias in the LT, especially at the SFC. But the IR experiment using the IASI data obtained the largest bias in the LT.

However, the RMSE is not always consistent with the bias profile in the temperature forecasts: in fact, the RMSE profile shows that the largest RMSE appeared in the LT and the smallest error in the MT. Compared to the CTRL experiment, the smaller RMSEs are only found in the MW experiment in the UT and LS, and the CON DA gave a positive contribution at the SFC and in the UT. The IASI DA experiment has a negative impact on the temperature forecast in the regional forecast system.

In contrast, all model forecasts overestimated the observed humidity except in the UT. The smallest bias in the humidity forecast occurred at the SFC and in the UT. Most of the DA experiments apparently reduced the bias in the LT to UT, especially for the IR DA experiment. But the MW DA obtained a larger bias than the CTRL experiment in the entire troposphere.

The RMSE in the humidity forecasts increases from the SFC to the LS, which is similar to the bias profile except in the UT. The largest error in the UT and LS is almost double the amount at the SFC. The DA experiments give a limited contribution to the humidity forecasts. The IR DA experiment does not improve the moisture forecast, although its smallest bias is found in the LT and MT.

\subsection{Discussion}

This is a study using the WRF-ARW mesoscale model linked to GSI data assimilation system to explore the impact of AMSU-A-MHS and IASI radiance data assimilation on the temperature and humidity forecasts in the different vertical layers over the west coast of United States. Due to the complexity of measurements for satellite instruments (such as the IASI with 8461 channels) and lack of knowledge in the estimation of impacts of those data sets in this regional area, forecasters should be aware of the limitations of this data assimilation when forecasting in this region.

The results show that the bias and forecast error are substantially related to the vertical layer of the objective. For example, the AMSU-A data assimilation reduced the temperature forecast bias in the upper atmospheric layers, and the conventional data assimilation indicates the best performance in the lower layer, but the IASI data assimilation shows worst performance in the lower layer. Compared to the largest bias in the upper atmospheric layer, the largest RMSE appeared in the lower atmospheric layer. For the humidity forecast there is a different behavior: the IASI data assimilation significantly reduced the bias in the troposphere, but the RMSE tells us that the IASI data assimilation does not improve the moisture forecast in this layer. The reason is very complicated; it is partially attributed to the data selection in the processes of data assimilation. IASI data have 8461 channels, but only 279 of those channels were used, based on pre- 
vious studies. Until now, it is not clearly understood what the main reason is for the different performances since many factors have contributed to the overall result. More experiments are necessary as part of our future study to try to understand the contributions from the various factors and components. The results shown in this analysis demonstrate the partial impact of satellite data on temperature and humidity forecasts in this region, but the positive or negative impact depends on the atmospheric layer and forecasts variables.

It is worth noting that the results presented here are based on one month's forecasts with three satellite instruments. The model performance needs to be examined with longer experiments and more data selection that extend to all available satellite data sets and more experiments from the different areas. As expressed by Manning and Davis (1997), "These statistics would provide additional information to model users and alert model developers to those research areas that need more attention."

Acknowledgements. The GSI data assimilation system was obtained from the Joint Center for Satellite Data Assimilation (JCSDA), the WRF-ARW model was obtained from the NCAR, and the satellite data sets were provided by NOAA/NESDIS/STAR. The authors would like to thank these agencies for providing the models and data. This work was supported by the Major State Basic Research Development Programme of China (973 Programme) (grant number 2013CB430101 and 2013CB430102), and a project funded by the Priority Academic Programme Development of Jiangsu Higher Education Institutions (PAPD); the National Natural Science Foundation of China (40701130, 41305013); the Not-for-Profit Industry (Meteorology) Research Program, China (GYHY201106027); and the Jiangsu Key Laboratory of Meteorological Observation and Information Processing (S5311026001) at the Nanjing University of Information Science and Technology, Nanjing, China.

This work was partially supported by the National Oceanic and Atmospheric Administration (NOAA); the National Environmental Satellite, Data, and Information Service (NESDIS); and the Center for Satellite Applications and Research (STAR). The views, opinions, and findings contained in this publication are those of the authors and should not be considered an official NOAA or U.S. Government position, policy, or decision.

Edited by: T. von Clarmann

\section{References}

Andersson, E., Hollingsworth, A., Kelly, G., Lönnberg, P., Pailleux, J., and Zhang, Z.: Global observing system experiments on operational statistical retrievals of satellite sounding data, Mon. Weather Rev., 119, 1851-1864, 1991.

Clerbaux, C., Boynard, A., Clarisse, L., George, M., Hadji-Lazaro, J., Herbin, H., Hurtmans, D., Pommier, M., Razavi, A., Turquety, S., Wespes, C., and Coheur, P.-F.: Monitoring of atmospheric composition using the thermal infrared IASI/MetOp sounder, At- mos. Chem. Phys., 9, 6041-6054, doi:10.5194/acp-9-6041-2009, 2009.

Collard, A. D.: Selection of IASI channels for use in numerical weather prediction, Q. J. Roy. Meteor. Soc., 133, 1977-1991, 2007.

Deber J.: Progress and Plans for the Environmental Modeling Center's (EMC) Gridpoint Statistical Interpolation (GSI) Development, available at: http://www.jcsda.noaa.gov/documents/ seminardocs/2012/Derber20120321.pdf (last access: 1 October 2015), 2012.

Derber, J. C. and Wu, W.-S.: The use of TOVS cloud-cleared radiances in the NCEP SSI analysis system, Mon. Weather Rev., 126, 2287-2299, 1998.

Eyre, J.: A bias correction scheme for simulated TOVS brightness temperatures, Tech. Memo., 186, ECMWF, 1992.

Han, Y., van Delst, P., Liu, Q., Weng, F., Yan, B., Treadon, R., and Derber, J.: JCSDA Community Radiative Transfer Model (CRTM) - Version 1, NOAA Tech Report 122, 2006.

Harris, B. and Kelly, G.: A satellite radiance bias correction scheme for data assimilation, Q. J. Roy. Meteor. Soc., 127, 1453-1468, 2001.

Kelly, G. A. and Flobert, J. F.: Radiance tuning, in: Technical Proceedings of the Fourth International TOVS Study Conference, Igls, Austria, 16-22 March 1988, 99-117, 1988.

Liu, Q. and Weng, F.: Detecting the warm core of a hurricane from the Special Sensor Microwave Imager Sounder, Geophys. Res. Lett., 33, L06817, doi:10.1029/2005GL025246, 2006a.

Liu, Q. and Weng, F.: Advanced doubling-adding method for radiative transfer in planetary atmosphere, J. Atmos. Sci., 63, 34593465, 2006b.

Liu, Z., Schwartz, C. S., Snyder, C., and Ha, S.-Y.: Impact of assimilating AMSU-A radiances on forecasts of 2008 Atlantic tropical cyclones initialized with a limited-area ensemble Kalman filter, Mon. Weather Rev., 4017-4034, 2012.

Manning, K. W. and Davis, C. A.: Verification and sensitivity experiments for the WISP95 MM5 forecasts, Weather Forecast., 12, 719-735, 1997.

McMillin, L. M., Crone, L. J., and Crosby, D. S.: Adjusting satellite radiances by regression with an orthogonal transformation to a prior estimate, J. Appl. Meteorol., 28, 969-975, 1989.

McNally, A. P., Derber, J. C., Wu, W., and Katz, B. B.: The use of TOVS level-1b radiances in the NCEP SSI analysis system, Q. J. Roy. Meteor. Soc., 126, 689-724, 2000.

Moncet, J., Uymin, G., and Snell, H. E.: Atmospheric radiance modeling using the Optimal Spectral Sampling (OSS) method, in: Preprints, SPIE Defense and Security Symp., Conf. 5425: Algorithms and Technologies for Multispectral, Hyperspectral, and Ultraspectral Imagery X, Society of Photo-Optical Instrumentation Engineers, Orlando, FL, 5425-5437, 2004

Parrish, D. F. and Derber, J. C.: The National Meteorological Center's spectral statistical interpolation analysis system, Mon. Weather Rev., 20, 1747-1763, 1992.

Rabier, F., Fourrié, N., Chafaï, D., and Prunet, P.: Channel selection methods for Infrared Atmospheric Sounding Interferometer radiances, Q. J. Roy. Meteor. Soc., 128, 1011-1027, 2002.

Rodgers, C. D.: Information content and optimisation of high spectral resolution measurements, in: Optical Spectroscopic Techniques and Instrumentation for Atmospheric and Space Research 
II, SPIE 2380, edited by: Hays, P. B. and Wang, J., 136-147, 1996.

Rodgers, C. D.: Inverse Methods for Atmospheres: Theory and Practice, World Scientific, Singapore, 2000.

Uddstrom, M.: Forward model errors, Proc. 6th Int. TOVS Study Conference, Airlie, Virginia, Cooperative Institute for Meteorological Satellite Studies, Space Science and Engineering Center, University of Wisconsin, USA, 501-516, 1991.

Wan, Q. and Xu, J.: A numerical study of the rainstorm characteristics of the June 2005 flash flood with WRF/GSI data assimilation system over south-east China. Hydrol. Process., 25, 1327-1341, doi:10.1002/hyp.7882, 2011.

Weng, F.: Advances in radiative transfer modeling in support of satellite data assimilation, J. Atmos. Sci., 64, 3799-3807, 2007.

$\mathrm{Xu}, \mathrm{J}$. and Powell, A.: Dynamical downscaling precipitation over the Southwest Asian: impacts of radiance data assimilation on the hindcasts of the WRF-ARW model, Atmos. Res., 111, 90103, doi:10.1016/j.atmosres.2012.03.005, 2012.
Xu, J., Rugg, S., Byerle, L., and Liu, Z.: Weather forecasts by the WRF-ARW model with the GSI data assimilation system in the complex terrain areas of Southwest Asia, Weather Forecast., 24, 987-1008, 2009.

Zapotocny, T. H., Jung, J. A., Le Marshall, J. F., and Treadon, R. E.: A two season impact study of four satellite data types and Rawinsonde data in the NCEP global data assimilation system. Weather Forecast., 23, 80-100, 2008.

Zhou, H., Gómez-Hernańdez, J. J., Hendricks Franssen, H.-J., and Li, L.: An approach to handling nongaussianity of parameters and state variables in ensemble kalman filtering, Adv. Water Resour., 34, 844-864, doi:10.1016/j.advwatres.2011.04.014, 2011. 